\title{
Study on Forging Quality Engineering of Human Resource Managers
}

\author{
Pingfang XIE \\ (Guangxi Technological College of Machinery and Electricity, Nanning, 530007 GuangXi)
}

Keywords: Enterprises, human resource managers, quality forging.

\begin{abstract}
China's rapid development of market economy and open market environment has brought a rare opportunity for development for Chinese enterprises nowadays, but also makes a lot of enterprises face a more intense challenge and competition at the same time. In the final analysis, the current economic competition is essentially a talent competition, Because of the human resources has the characteristics that it can not be copied, as well as its strong growth potential, big return space, it has become the primary resource and core competitiveness of enterprises. For today's enterprises, it is essential for the modern enterprise survival and development to exploit the potential of human resources fully. Development of talent advantage is closely related to human resource management, therefore, it's the key to fully understand the current situation of the quality of human resource management, and constantly improve the level of human resource management. Therefore, this article is committed to exploring specific programs of quality human resource managers forged.
\end{abstract}

\section{Introduction}

Technology, management system, quality of service are decisive conditions for continuous development of enterprises, and this is closely related to the overall quality and the level of skills of employees, which ultimately depends on human resource management. However, different individuals have different personalities, it is not easy to manage staff for businesses, therefore, the level of corporate human resource management has become a major bottleneck restricting the development of enterprises. A foreign data show that if fixed assets increase $1 \%$, productivity can be increased accordingly by $0.2 \%$, however, if an enterprise introduce $1 \%$ talent more, productivity can be increased by $1.8 \%$, they are in stark contrast. This shows that management is actually an important source of organizational efficiency, management is productivity. The perpetrators of management is human, therefore, the training and development of personnel management is very important. The level and skills of management is a manifestation of the overall quality of the people, it needs a rich store of knowledge and experience to precipitate and can not easily trained, so it is a challenging project to forge quality management personnel, and it has great value for its research and exploration. This paper analyzed the organization's current shortage of human resources management and its reasons first, further elaborated the current generic quality model of human resource managers, finally explored the specific embodiments of forging quality of human resource management.

\section{Insufficient and reasons of human resource management}

The current shortage of human resource management is mainly reflected in the following aspects: 
(1) the majority of senior corporate executives did not analyze and plan corporate human resources function and work positioning integrally, either without sufficient coordination with other departments, on the whole, universal attention is not enough.

(2) Human resources management did not play its overall function and effect, it is mutual scattered among the plates, and had no effective integration.

(3)Human resource managers' daily work is busy with their work among the multifarious trivial, enterprises did not put it in a strategic position to help the development of enterprises either.

(4)Enterprise has not enough incentive to employees, there is no effective institutional mechanisms in spiritual and material.

There are many reasons for these problems, the whole concept of subjective awareness is not strong, objective lack of appropriate institutional guarantee. But for businesses, the quality level of human resources managers of the city largely influences the change in human resources management by overall staff awareness and positioning of human resources in the system, Therefore, the most important factor is human resource management personnel quality level and lack of the related concept of consciousness. In addition the quality of human resources managers also decided directly whether HR can carry out efficiently and systematically eventually. It can be seen, human resource management has an important function for the development of enterprises, but now, a lot of corporate human resources management are not fully play its original effectiveness, therefore, the management of human resource management is a challenging quality forging works.

\section{Analysis of general quality model on China's current human resource managers}

Quality refers to a person doing a job compared to the general population have the advantage, or characteristic, it can be called a qualified conditions or competency. The current human resources management personnel quality is not high, mainly in the lack of professional systems training, vocational skills, not deep enough understanding of human nature, how to choose, employing, keep people for enterprise. Therefore, to establish a reasonable and effective competency model of human resource managers, it must be based on adequate knowledge of human resource management positions and jobs, and its detailed analysis of work.

Currently, the main functions of modern human resource management constituted by four plates, they are attract and maintain talent, use and development of human resources, have a good employee motivation, communication and care, develop effective resource management policies to improve use efficiency of human resources, promote the development and innovation of enterprises. We can see human resource manager plays a variety of roles in the enterprise, firstly, he must be a human resource management expert, secondly, he is the spokesman for the interests of employees, finally, he is a corporate strategic partner and provide support for the development of enterprises which requires he become a highly qualified staff rolled into a variety of roles.

After field research on local businesses combined with related research on the human resource, established the following universal competency model of human resource management shown as table 1. Through analysis of relevant research data of several companies, got the right quality of each weight.

We can see from the table the most important qualities are team influence, communication and understanding and education and training capacity. Although the nine qualities listed in the table can not represent all quality types that human resources managers possess, but it has included the major part of quality features, it still have a relatively strong informative, in specific applications, enterprises can modify the model according to their own circumstances. 
Table 1 Universal competency model of human resource management

\begin{tabular}{|c|c|c|}
\hline Quality name & Weight (out of 100) & Sequence \\
\hline $\begin{array}{l}\text { NoteProfessional knowledge and } \\
\text { in } \quad \text { skills }\end{array}$ & 9.6 & 6 \\
\hline $\begin{array}{cc} & \text { Communication and } \\
\text { my } & \text { understanding } \\
\end{array}$ & 12.3 & 3 \\
\hline Teamwork & 9.8 & 5 \\
\hline Relationship building & 12 & 4 \\
\hline Control ability & 7.5 & 9 \\
\hline Education and training & 15.5 & 1 \\
\hline Customer service & 9.3 & 7 \\
\hline $\begin{array}{l}\text { Inductive and deductive } \\
\text { thinking }\end{array}$ & 9 & 8 \\
\hline Team influence & 15 & 2 \\
\hline
\end{tabular}

research resulting from Human Resources in some enterprises in the year 2005-2015

\section{Implementation of human resource management personnel quality forging works}

We usually call human resources development and training for forging. Development of human resources based on the future development of enterprises, educate employees on the future knowledge and skills that duties require, which is a relatively far-sighted investment, therefore, it will also give enterprises a lasting competitive edge. While training is to educate knowledge, skills and attitudes that employees need in currently working and quickly applied to work to bring more obvious short-term effects for enterprises. Development and training has a very important significance for enterprises. Firstly, it can enhance their sense of belonging and loyalty to the enterprise, secondly, it can reduce the cost and improve work efficiency. For businesses, to fully tap the potential and utilization of human resources, ensure the common progress of enterprises and employees, allowing companies to obtain considerable development ultimately and is a foothold for corporate training and development. Therefore, investment in human capital has incomparable significance compared to other investments.

Relationship between human resource management training and development is actually complementary. First, they both belong to the same teaching and learning activities, There are many similarities in the method of implementation ,they can learn and complement from each other. Second, it realized part of the development function actually when training, this is because the training can not only improve their skills, wealth of knowledge and new ideas, but also enhance the quality and inspire potential. Thus to some extent, their methods have many similarities, and also possess of communicating effect, so use both of them in this paper.

Human Resource Management forging quality project must be an organic system, it should be able to resolve the current human resource management issues firstly, then it need to have the human resource strategy functions. They all must be included in this system that the subject of implementation, the method of implementation, the implementation process and the principle of the implementation.

1.The subject of implementation. Here the subject refers to the main business development 
training, mainly refers to the internal autonomy training. Independent training includes two aspects, first is about their own system and internal knowledge, companies can train by itself, but sometimes its own internal resources relatively limited, when facing with some of the latest knowledge and skills, companies often seek more specialized training institutions and vocational education institutions outside to train.

2.The method of implementation. Here generally refers to the type and mode of training development. Type of training and development include job training and off-job training. The way to take job training are staff development meetings, special assignments, mentoring, with the guidance of a teacher, substitute succession training, job rotation and so on. The job training is not departing from job, in contrast with the off-job training. The way to take off-job training are seminar, conference outside the enterprise, evening or job training, advanced management training. Staff can acquire knowledge more systematic and comprehensive in job training compared to off-job training, but off-job training can get more targeted training.

With particular emphasis on students' mastery of knowledge and skills, and the ability to comprehend, experience feelings, etc. in the process of training and development, it decided by the practicality and application of human resources management knowledge and skills. At this moment, there are so many new training development methods, for example, Personalized training, e-learning, practical training, subject practice, practice and so on. To conclude, it can be classified as follows. The first is the scenario simulation method. Simulate the work context, to make students analyze and thinking about the management problems encountered in live and give solutions. The form of simulated situations varies, such as role-playing method, a leaderless group discussion method, game management method. The heuristic teaching followed by. In training development, It is not conducive for simply taught to convert knowledge to the ability and is not sufficient for solving the specific management problems, accordingly, the use of interactive, problem-based heuristic teaching is especially important. Finally, the case study method. Guide the trainee actively In the development and training, should not judge too much so as not to affect their independent thinking to ensure the best results of the training largely, therefore, it is an inductive approach to learning.

3.The implementation process. First, for the realization of the training incentive effects, to avoid training being a mere formality, it is a prerequisite to analyze human resource management positions, occupies of a position and personal competence conditions.

A reasonable implementation process of training should consist of the following steps.(1) Human resources management department organizational analysis.(2) To develop appropriate training plans and goals, try to quantify or qualitative training objectives to ensure their operability.(3) After determining the training objectives, it is needed to select the appropriate training content and training methods to implement training programs.(4) Finally, evaluate student assessment results and evaluation of student training and the assessment of student performance in future work in addition.

4.The principle of the implementation. We should adhere the problem-oriented principle in the process of the project that forging the quality of human resource managers. Currently, general knowledge and comprehensive quality about management of human resource management staff in the enterprise is not high, relevant expertise at their disposal is insufficient, these are all reflect of the low quality of current human resource managers. To deal with these problems, we should combine the current situation of enterprises, stage of development and strategic objectives with industry characteristics to select the appropriate training methods, improve the practical training, thereby enhancing the speed to convert knowledge to ability and performance. Second, adhere to the 
principles of relevance and practicality, adhere to the concept of training to apply to their knowledge. Take classification training for different people and circumstances with different methods and content, so that employees can learn knowledge and skills which is consistent with the requirements of the job.

\section{Summary}

China's market economy has made remarkable achievements nowadays, and continue to integrate into the tide of globalization, domestic and foreign markets began to be integration, this has brought a lot of opportunities to domestic market, but make China's economy be facing greater challenges. Market continued to select the superior and eliminate the inferior that business competition are increasing. Therefore, enterprises should keep pace with the times, innovate and strengthen functions strategic of human resource management.

In summary, corporate HR training employees mainly in the following areas,(1) Most current human resources management concept and the most cutting-edge management theory and technology.(2) Training the human resources directors to enhance their business management knowledge and skills.(3) Adaptability training to give directions to new employees.(4) From the viewpoint of improving professional skills, take candidates training, promotion education and training for junior staff.(5) Because department heads themselves actually bear the part of human resources management work, so they have to take the appropriate human resources management training, They can train the job analysis, performance evaluation, staff selection, etc. in order to coordinate the work of the HR department better to some extent. Finally become an efficient human resource management, help enterprises develop better, grow more in the fierce competition in the market, realize forging quality of human resource management

\section{References}

[1] Peng Jianfeng, Jin Xiaojuan, Employee quality model design, Chinese People University Press, Beijing, 2003.

[2] Ren Junzheng, Best management training "hard up", J. Human Resource Development. 3 (2008).

[3] Employee management study group, Employee Training Methods, China Economic Publishing House, Beijing, 2002.

[4] Yu Mei, Three major issues facing with corporate management training, J. Vocational Education Research. 3 (2005).

[5] Shi Jintao, Modern Human Resources Development and Management, Shanghai Jiaotong University Press, Shanghai, 2004.

[6] Chen Wei, Zhang Zhiling, Optimization of Human Resource Management Training System, J. Enterprise Herald. 3 (2009). 